\title{
Clomiphene Citrate
}

National Cancer Institute

\section{Source}

National Cancer Institute. Clomiphene Citrate. NCI Thesaurus. Code C379.

The citrate salt form of clomiphene, a triphenylethylene nonsteroidal ovulatory stimulant evaluated for antineoplastic activity against breast cancer. Clomiphene has both estrogenic and anti-estrogenic activities that compete with estrogen for binding at estrogen receptor sites in target tissues. This agent causes the release of the pituitary gonadotropins follicle stimulating hormone (FSH) and luteinizing hormone (LH), leading to ovulation. ( $\mathrm{NCl04)}$ 